\title{
Advanced Small Intestinal Neuroendocrine Carcinoma
}

National Cancer Institute

\section{Source}

National Cancer Institute. Advanced Small Intestinal Neuroendocrine Carcinoma. NCI

Thesaurus. Code C156687.

A small intestinal neuroendocrine carcinoma that has spread extensively to other anatomic sites or is no longer responding to treatment. 